\title{
Extreme precipitation strengthening in ion-implanted nickel
}

\author{
J. A. Knapp, S. M. Myers, D. M. Follstaedt, and G. A. Petersen
}

Sandia National Laboratories, Albuquerque, NM 87185-1056

\begin{abstract}
Precipitation strengthening of nickel was investigated using ion-implantation alloying and nanoindentation testing for particle separations in the nanometer range and volume fractions extending above $10 \%$. Ion implantation of either oxygen alone or oxygen plus aluminum at room temperature was shown to produce substantial strengthening in the ion-treated layer, with yield strengths near $5 \mathrm{GPa}$ in both cases. After annealing to $550^{\circ} \mathrm{C}$ the oxygen-alone layer loses much of the benefit, with its yield strength reduced to $1.2 \mathrm{GPa}$, but the dual ion-implanted layer retains a substantially enhanced yield strength of over $4 \mathrm{GPa}$. Examination by transmission electron microscopy showed very fine dispersions of $1-5 \mathrm{~nm}$ diameter $\mathrm{NiO}$ and $\gamma-\mathrm{Al}_{2} \mathrm{O}_{3}$ precipitates in the implanted layers before annealing. The heat treatment at $550^{\circ} \mathrm{C}$ induced ripening of the $\mathrm{NiO}$ particles to sizes ranging from 7 to $20 \mathrm{~nm}$, whereas the more stable $\gamma-\mathrm{Al}_{2} \mathrm{O}_{3}$ precipitates were little changed. The extreme strengthening we observe is in semiquantitative agreement with predictions based on the application of dispersion-hardening theory to these microstructures.
\end{abstract}

\section{Introduction}

The theory of dispersion hardening indicates that very high levels of strength in a metal may be attained by introducing a dense distribution of very small, hard precipitates to impede dislocation motion; to first order, yield stress is predicted to vary inversely with particle separation. ${ }^{1}$ In this study we have demonstrated such hardening in Ni using ion implantation to form nanometer-size precipitates of either $\mathrm{NiO}$ or $\gamma-\mathrm{Al}_{2} \mathrm{O}_{3}$, or both together, at volume fractions exceeding $10 \%$ in the $\mathrm{Ni}$ matrix. Micromechanical testing analyzed by finite-element modeling was used to quantify the elastic and plastic properties of the treated zone and to show that the resulting strengths are indeed substantially greater than those reported from conventional metallurgical processing. Transmission electron microscopy (TEM) was employed to characterize precipitate microstructure. The mechanism and size of the strengthening are similar to those observed in $\mathrm{Al}$ during previous research at our laboratory, where ion implantation of $\mathrm{O}$ into $\mathrm{Al}$ produced very fine-scale dispersions of $\gamma-\mathrm{Al}_{2} \mathrm{O}_{3}$ precipitates. ${ }^{2-5}$ The resulting $\mathrm{Al}$ alloys were exceptionally strong and displayed greatly 


\section{DISCLAIMER}

Portions of this document may be illegible in electronic image products. Images are produced from the best available original document. 
improved friction and wear characteristics compared to conventional $\mathrm{Al}$ alloys. ${ }^{5}$ For the present study in $\mathrm{Ni}$, we find that implanting either $\mathrm{O}$ alone (forming $\mathrm{NiO}$ precipitates) or $\mathrm{O}$ followed by $\mathrm{Al}$ (converting much of the $\mathrm{NiO}$ to $\gamma-\mathrm{Al}_{2} \mathrm{O}_{3}$ or $\mathrm{NiAl}_{2} \mathrm{O}_{4}$ precipitates) results in a surface layer with a yield strength near $5 \mathrm{GPa}$. Annealing the O-implanted sample at $550^{\circ} \mathrm{C}$ for 2 hours ripens the $\mathrm{NiO}$ precipitates substantially, resulting in a loss of benefit, but after the same anneal the dual ion implanted sample exhibits only small $\gamma-\mathrm{Al}_{2} \mathrm{O}_{3}$ precipitates and still exhibits a yield strength over 4 $\mathrm{GPa}$. A further important observation is that the hardened $\mathrm{Ni}\left(\gamma-\mathrm{Al}_{2} \mathrm{O}_{3}\right)$ and $\mathrm{Ni}(\mathrm{NiO})$ layers retain ductility, as evidenced by the absence of cracking or delamination under severe deformation during nanoindentation testing.

In both the previously studied $\mathrm{Al}$ and the present $\mathrm{Ni}$, the alloys gain their strength because of an extremely fine microstructure of hard precipitates $(1-5 \mathrm{~nm})$ dispersed throughout the metallic matrix at depths up to $\sim 0.5 \mu \mathrm{m}$. Our motivations for extending these studies to $\mathrm{Ni}$ included further testing of the theory of dispersion hardening in the regime of extreme particle refinement, exploration of the limits of strength attainable with $\mathrm{Ni}$, and surface hardening of $\mathrm{Ni}$ components in microelectromechanical systems. Since the mechanical properties of the Ni matrix are very different from those of $\mathrm{Al}$, with the shear modulus being a factor of 3 greater, the investigation of both metal hosts provides a more stringent test of our understanding of the strengthening mechanisms involved.

\section{Experimental procedures}

\section{Sample preparation}

Seven different sample conditions were prepared and examined: unimplanted $\mathrm{Ni}$, $\mathrm{Ni}$ implanted with $\mathrm{O}$ alone, $\mathrm{Ni}$ implanted with $\mathrm{Al}$ alone, $\mathrm{Ni}$ implanted with both $\mathrm{O}$ and $\mathrm{Al}$, and the same three implanted samples after a $550^{\circ} \mathrm{C}$ anneal. The starting material was Ni with a nominal purity of $99.99 \%$, annealed at $1000^{\circ} \mathrm{C}$ for 2 hours in vacuum. This anneal resulted in observable grain relief with a typical grain size between 200 and $500 \mu \mathrm{m}$. For mechanical testing a $\sim 1 \mathrm{~mm}$ thick disk was used for the base material, while microstructural examinations were carried out on $\mathrm{Ni}$ foil samples subjected to the same implantations and anneals. The implantations consisted of multiple energies and fluences, chosen in order to produce regions of approximately uniform composition, with $\sim 8$ at.\% each of $\mathrm{Al}$ and $\mathrm{O}$ to a depth of $200 \mathrm{~nm}$ below the surface. The combinations were chosen using TRIM Monte Carlo simulations ${ }^{6}$ of the implant depth profiles with confirmation by ion-beam profiling as discussed below. For $O$ the implantation conditions were: $3.0 \times 10^{16}$ atoms $/ \mathrm{cm}^{2}$ at 50 $\mathrm{keV}, 3.33 \times 10^{16}$ atoms $/ \mathrm{cm}^{2}$ at $100 \mathrm{keV}$, and $8.5 \times 10^{16}$ atoms $/ \mathrm{cm}^{2}$ at $150 \mathrm{keV}$. For $\mathrm{Al}$ the conditions were: $2.0 \times 10^{16}$ atoms $/ \mathrm{cm}^{2}$ at $50 \mathrm{keV}, 2.0 \times 10^{16}$ atoms $/ \mathrm{cm}^{2}$ at $100 \mathrm{keV}$, and $1.0 \times 10^{17}$ atoms $/ \mathrm{cm}^{2}$ at 
$180 \mathrm{keV}$. The implantations were carried out at room temperature in a turbomolecular-pumped vacuum of approximately $3 \times 10^{-5} \mathrm{~Pa}\left(2 \times 10^{-7} \mathrm{Torr}\right)$.

\section{Depth profile measurements}

The depth profiles of $\mathrm{O}$ and $\mathrm{Al}$ were measured using $\mathrm{He}^{4}$ backscattering ion beam analysis. Two $\mathrm{He}^{4}$ energies were used, $2.5 \mathrm{MeV}$ for optimum depth resolution and $8.6 \mathrm{MeV}$ for optimum sensitivity to $O$ (with an enhanced, non-Rutherford cross-section), and the results were analyzed using the simulation program SIMNRA. ${ }^{7}$ An iterative analysis was used with the results from both energies to deduce the concentration profiles.

\section{Transmission electron microscopy}

TEM at $200 \mathrm{keV}$ was used to characterize the microstructure of $\mathrm{Ni}$ implanted with $\mathrm{O}$ alone as well as with both $\mathrm{O}$ and $\mathrm{Al}$ as described above. The microstructure of $\mathrm{Ni}$ implanted with $\mathrm{Al}$ alone was not examined, since previous work had shown that it would form an fcc solution. ${ }^{8}$ Images were obtained in both cross section and plan-view, principally using dark-field or underfocussed imaging techniques to produce contrast on the oxide precipitates that form. Electron diffraction patterns were used to identify the oxide phases present after implantation as well as after subsequent annealing.

Cross-sectional TEM was used to determine the depth-dependence of microstructures in the implanted region. Specimens were prepared by "sandwiching" implanted Ni foils between pieces of Si wafer with epoxy, and coring a cylinder with its axis at the implanted surface. Disks were cut from the cylinder and were mechanically thinned using standard metallographic techniques. Final thinning was done by ion milling with Ar at low angles.

Plan-view TEM provided complementary information and gave the best electron diffraction patterns for phase identification. Specimens were prepared from implanted Ni foils by backthinning. The specimen was first metallographically dimpled, and thinning was completed by jet electro-polishing with a nitric acid solution.

\section{Nanoindentation measurements}

The strength and elasticity of the implanted layers were measured using nanoindentation, wherein a small three-sided Berkovich-shaped diamond indenter is used as a probe, and the force required for insertion is recorded as a function of position. ${ }^{9-13}$ The displacement and load resolutions can be as low as $0.02 \mathrm{~nm}$ and $50 \mathrm{nN}$, respectively. Nanoindentation is often performed with a single insertion to a specified depth, followed by withdrawal; the force during insertion depends on both elastic and plastic deformation, while the contact stiffness (derivative of force with depth) upon 
withdrawal is dependent only on the elastic behavior. For the present samples we used a dynamic indentation technique, the Continuous Stiffness Measurement (CSM), which superimposes an ac modulation on the applied loading force, resulting in a continuous oscillation of about $1 \mathrm{~nm}$ as the indenter is inserted. The response of the sample, as characterized by the phase and amplitude of the oscillating displacement, gives the contact stiffness as a continuous function of depth. ${ }^{11}$ In the more conventional measurement, the stiffness is obtained only at the deepest penetration, when the indenter is withdrawn. The additional stiffness information as a function of depth provided by the CSM approach is particularly valuable when examining ion-implanted samples, since the shallow depth of the treated layer and variations of the implanted concentration with depth significantly complicate the analysis of the results.

\section{Finite-element modeling of nanoindentation}

Separating the contributions of the surface layer and the substrate to the observed nanoindentation data for the present implanted samples is difficult to accomplish using a standard analytical approach. In order to extract quantitative values for the yield strength and Young's modulus of the implanted layer, a detailed analysis using finite-element modeling is required, not only to separate the properties of the layer from those of the underlying soft substrate, but also to account for variations of the properties with depth in the ion-treated layer itself. ${ }^{14-20}$ In this analysis, which we have applied to nanoindentation data from a number of thin layer materials, we use the commercial, large-strain, finite-element code ABAQUS/Standard ${ }^{21}$ to calculate the combined indentation response of the layer and substrate, with our own software utilities being employed to generate meshes and depth-dependent material descriptions specific to each sample and to fit the results. Rounding of the indenter tip and friction between tip and surface are included in the modeling, but time-dependent behavior (creep) is not. The depth variation of mechanical properties of the implanted layer, as well as the mechanical properties of the substrate and of the diamond indenter tip, are described as closely as possible in the model. The yield strength $Y$ (defined at a plastic strain of 0.002 ) and Young's elastic modulus $E$ for the ion-implanted regions are then varied in a series of simulations of the nanoindentation experiment until good matches to the load and stiffness data are obtained for all depths. Using curve fitting and appropriate extrapolations, the conditions for a good fit to the data can often be obtained using as few as 5-6 simulations.

Hardness is a parameter more commonly used than yield strength for comparing the mechanical properties of surfaces, since it is deduced directly from indentation experiments on bulk materials and provides a convenient measure of large-strain plastic response. The hardness, defined here as force per unit of projected contact area during contact under load, is available at any step of a finite- 
element simulation by dividing the force by the calculated projected area of the contact between the indenter and the top surface. Of course, for the simulations of the implanted layers this is still the combined hardness of layer plus substrate, just as for a conventional analysis of the data. The procedure above for deducing $\mathrm{Y}$ and $\mathrm{E}$ for the layer does not directly give the hardness of the layer material alone. To separately obtain the peak hardness of the layer material we do an additional simulation with a hypothetical, semi-infinite bulk "sample" using the peak $Y$ and $E$ values already deduced for the layer material. This simulated nanoindentation response using only the layer material gives a value of hardness which can then be compared directly to measurements of bulk materials or to other layers of differing thicknesses or on differing substrates.

\section{Results: concentration profiles}

Figure 1 shows representative concentration profiles measured using ion beam analysis, in this case after implantation of both $\mathrm{O}$ and $\mathrm{Al}$, followed by the $550^{\circ} \mathrm{C}$ anneal. The solid line in Fig. 1 is the inferred profile of yield strength as a function of depth in the sample, to be discussed below. Ion backscattering spectrometry measures an areal density of atoms, so a material atomic density has to be assumed to obtain a linear depth scale. For simplicity, the atomic density for pure $\mathrm{Ni}\left(9.14 \times 10^{22}\right.$ atoms $/ \mathrm{cm}^{3}$ ) was used here.

Although the ion beam analysis for these two light elements in $\mathrm{Ni}$ is not as accurate as for heavier elements, the profiles shown in Fig. 1 give an approximate indication of the implanted ion distributions after the anneal, with the $\mathrm{O}$ and $\mathrm{Al}$ overlapping over a region more than $200 \mathrm{~nm}$ in width. Before the anneal, the as-implanted profile of $\mathrm{Al}$ was about the same width and reached 10.5 at.\%., while the as-implanted $O$ profile extended about $25 \mathrm{~nm}$ deeper and reached 9 at.\%. After the anneal (Fig.1) the peak $\mathrm{Al}$ concentration is 9.7 at.\% and the peak $\mathrm{O}$ concentration is 7.5 at.\%. The implantations were intentionally $\mathrm{Al}$-rich relative to the stochiometry of $\gamma-\mathrm{Al}_{2} \mathrm{O}_{3}$ precipitates in order to minimize the formation of competing oxide phases such as $\mathrm{NiO}$ and $\mathrm{NiAl}_{2} \mathrm{O}_{4}$ spinel once the layer had been annealed. While this left excess $\mathrm{Al}$ in the implanted region, the effect of $\mathrm{Al}$ by itself on the mechanical properties of the layers is substantially smaller than that of the precipitate strengthening, as we show below.

The anneal condition of $550^{\circ} \mathrm{C}$ for 2 hours was chosen to optimize the formation of $\gamma-\mathrm{Al}_{2} \mathrm{O}_{3}$ precipitates in the implanted region. The diffusion coefficient of $\mathrm{Al}$ in $\mathrm{Ni}$ at $550^{\circ} \mathrm{C}$ is only $3.0 \times 10^{-17} \mathrm{~cm}^{2} / \mathrm{s}$, as extrapolated from published data ${ }^{22,23}$, so the unenhanced diffusion distance for $\mathrm{Al}$ after 2 hours is about $5 \mathrm{~nm}$. On the other hand, the diffusion coefficient for $\mathrm{O}$ under the same 
conditions is extrapolated to be $1.9 \times 10^{-12} \mathrm{~cm}^{2} / \mathrm{s}^{24}$ so the diffusion distance for $\mathrm{O}$ in 2 hours is about $1200 \mathrm{~nm}$. However, the solubility of $\mathrm{O}$ in $\mathrm{Ni}$ at $550^{\circ} \mathrm{C}$ is only $2.4 \times 10^{18} \mathrm{~cm}^{-3}$, ${ }^{24}$ so the amount in a $1200 \mathrm{~nm}$ diffusion tail would be $\sim 3 \times 10^{14}$ atoms $/ \mathrm{cm}^{2}$, much less than the implanted total. Thus, in the absence of $\mathrm{Al}$ most of the $\mathrm{O}$ would remain in place during the anneal, ripening the $\mathrm{NiO}$ precipitates which form upon implantation. If $\mathrm{Al}$ is present, the $\mathrm{O}$ is expected to diffuse to it and form the much more thermodynamically stable $\gamma-\mathrm{Al}_{2} \mathrm{O}_{3}$ precipitates, which in turn would not be expected to ripen significantly. Our measurements of the profiles confirm these predictions, as do the observed microstructures, as will be discussed next.

\section{Results: microstructure}

\section{Ni implanted with $\mathrm{O}$}

The implantation of $\mathrm{O}$ alone into $\mathrm{Ni}$ was found to produce precipitates that were identified as $\mathrm{NiO}$ using electron diffraction and were imaged in plan-view with dark-field methods, as seen in Fig. 2. The diffraction pattern in Fig. 2(a) is a $<001>$ zone-axis orientation of the fcc Ni matrix, which produces the square array of bright reflections. Radially inward from each Ni reflection is a weak reflection due to the precipitates. By using the known lattice spacings of the fcc $\mathrm{Ni}$ reflections as an internal standard for the pattern, the lattice spacings for the weak reflections can be determined with $1 \%$ or better accuracy; the measured values fit the known spacings of cubic $\mathrm{NiO}$ (listed in Table I) to within this error. Furthermore, each weak reflection fits an NiO reflection with the same reciprocal lattice indices as its nearby $\mathrm{Ni}$ reflection, i.e., the (200) $\mathrm{NiO}$ spot is found just inside the (200) Ni reflection. This correspondence indicates that the cubic lattice axes of NiO coalign with those of the fcc Ni matrix. Because the Ni matrix is strongly diffracting and we are examining weak reflections, other weak spots also appear around each $\mathrm{Ni}$ reflection due to multiple diffraction by $\mathrm{Ni}$ and then NiO.

Dark-field imaging with the weak reflections was used to illuminate the NiO precipitates as seen in Fig. 2(b). To obtain relatively sharp images, the TEM astigmatism controls were re-aligned to correct for distortions in the lenses due to the magnetic Ni specimens. A dense array of precipitates is seen with most of their diameters falling in the range $1.5-3.5 \mathrm{~nm}$. This size range is believed to be typical of $\mathrm{NiO}$ that precipitated within the O-implanted Ni. Some larger precipitates are also seen, occasionally as large as $\sim 10 \mathrm{~nm}$. We believe it likely that the large nickel oxides formed on the surface of the thinned TEM specimen. Examination of diffraction patterns from the thinnest areas also reveal very weak rings matching $\mathrm{NiO}$ that are believed due to randomly oriented oxide 
particles on the surface. Segments of such rings are necessarily included when the objective aperture is placed on the $\mathrm{NiO}$ spots for dark-field imaging, thus allowing some larger surface oxides to be illuminated also.

\section{Ni implanted with $\mathrm{O}$ and annealed 2 hours at $550^{\circ} \mathrm{C}$}

Annealing $\mathrm{O}$-implanted $\mathrm{Ni}$ for 2 hours at $550^{\circ} \mathrm{C}$ ripened the $\mathrm{NiO}$ precipitates and produced a wide distribution of sizes. The NiO reflections are sharper because the precipitates are larger but occur at the same positions in diffraction patterns, indicating that the same alignment with the $\mathrm{Ni}$ matrix was retained. A dark-field image of these larger precipitates is shown in Fig. 2c. The precipitates are seen to have a cuboidal shape when viewed near the [100] matrix orientation as in Fig. 2c. This shape reflects their cubic lattice symmetry and the co-alignment of their cubic directions with those of the fcc Ni matrix. The size distribution was determined to have an average cube edge length of $13.5 \mathrm{~nm}$, with an RMS width of $6.2 \mathrm{~nm}$.

\section{Ni implanted with $\mathrm{O}$ and $\mathrm{Al}$}

Surface layers of $\mathrm{Ni}$ implanted with $\mathrm{O}$ followed by $\mathrm{Al}$ were examined in the as-implanted condition and after the subsequent 2 hour anneal at $550^{\circ} \mathrm{C}$. The two treatments were compared using cross-sectional TEM as seen in Fig. 3. The as-implanted condition is shown in Fig. 3(a); in this image, the specimen was tilted away from high-symmetry orientations producing strong diffraction and associated high contrast for numerous dislocations found in the implanted layer. The specimen was then imaged in an underfocussed condition to produce Fresnel contrast on the oxide precipitates, since their average atomic number is lower than that of the Ni matrix. Just below the surface and extending to $\sim 150 \mathrm{~nm}$ depth, the contrast highlights smaller particles with light centers that are 2-3 nm across. However, between $\sim 100$ to $220 \mathrm{~nm}$ in depth, larger particles 7 $10 \mathrm{~nm}$ in diameter are seen highlighted with a dark edge around their lighter center.

The two differing particle sizes suggest that two types of precipitates are present in this specimen. Phases likely to have been formed in this material are the cubic structures $\gamma-\mathrm{Al}_{2} \mathrm{O}_{3}$, $\mathrm{NiAl}_{2} \mathrm{O}_{4}$, and $\mathrm{NiO}$; key information about their lattice spacings and structures is given in Table I. The identity of the two phases is suggested by their sizes and by the $\mathrm{Al}$ and $\mathrm{O}$ profiles determined for $\mathrm{Ni}$ implanted with $\mathrm{Al}$ and $\mathrm{O}$ before annealing. The smaller precipitates near the surface are thought to be either $\mathrm{NiAl}_{2} \mathrm{O}_{4}$ or $\gamma-\mathrm{Al}_{2} \mathrm{O}_{3}$ because the composition profiles of as-implanted $\mathrm{Al}$ and $\mathrm{O}$ (not shown) overlap well in this depth interval, and since similar small precipitates are found after 
annealing and are identified as $\gamma-\mathrm{Al}_{2} \mathrm{O}_{3}$ (below). Beyond $\sim 160 \mathrm{~nm}$ depth the $\mathrm{Al}$ profile drops, but the $\mathrm{O}$ profile is relatively constant to a depth of $\sim 200 \mathrm{~nm}$. Since the $\mathrm{Al}$ concentration is reduced at these depths and larger precipitates are seen in $\mathrm{Ni}$ implanted with $\mathrm{O}$ alone (see above), we suggest that the larger precipitates near the back of the implanted layer are $\mathrm{NiO}$. They may be larger than the average size observed in plan view in the $\mathrm{O}$-alone sample because of fewer nucleation sites near the back end of the $\mathrm{O}$ profile. Electron diffraction from the cross-section specimen shows some reflections that fit $\mathrm{NiO}$ better than the other two phases, as well as some that match the spacings of the two spinel-type phases; $\mathrm{NiAl}_{2} \mathrm{O}_{4}$ fits them somewhat better but $\gamma-\mathrm{Al}_{2} \mathrm{O}_{3}$ is not ruled out. Thus both $\mathrm{NiO}$ and an oxide incorporating the implanted $\mathrm{Al}$ are thought to be present after roomtemperature implantation of $\mathrm{Al}$ and $\mathrm{O}$.

\section{Ni implanted with $\mathrm{O}$ and $\mathrm{Al}$ and annealed 2 hours at $550^{\circ} \mathrm{C}$}

The precipitate microstructure changes after $\mathrm{Ni}$ implanted with $\mathrm{O}$ and $\mathrm{Al}$ is annealed 2 hours at $550^{\circ} \mathrm{C}$, as seen by comparing Fig. 3(b) with 3(a). After annealing, the corresponding crosssectional view shows only fine precipitates $\sim 2 \mathrm{~nm}$ in diameter when imaged in an underfocussed condition. The precipitates appear to extend a bit deeper than the fine precipitates in Fig.3a, to at least $240 \mathrm{~nm}$, which agrees well with the $\mathrm{Al}$ and $\mathrm{O}$ profiles in Fig. 1 obtained after annealing. Their phase is identified using electron diffraction patterns taken in plan-view, such as Fig. 4(a). This [01-3] zone axis pattern and other orientations shows weak reflections just inside the intense ones of fcc Ni, similar to $\mathrm{NiO}$ in Ni. By using the Ni reflections as internal standards, lattice spacings of 1.975 and $1.375 \AA$ of these spots are determined with better than $1 \%$ accuracy as detailed in Table I. The lattice spacings differ by $\sim 5 \%$ from those of $\mathrm{NiO}$, but match $\gamma-\mathrm{Al}_{2} \mathrm{O}_{3}$ precisely. Moreover, the spacings for $\mathrm{NiAl}_{2} \mathrm{O}_{4}$ are also outside the error limits for the observed reflections. During the anneal, the highly exothermic reaction of $\mathrm{O}$ and $\mathrm{Al}$ would be expected to go to completion before $\mathrm{O}$ reacts less energetically with $\mathrm{Ni}$. Since excess $\mathrm{Al}$ is present, all the $\mathrm{O}$ is expected to form $\mathrm{Al}_{2} \mathrm{O}_{3}$. The $\gamma$ phase is thus energetically preferred over $\mathrm{NiAl}_{2} \mathrm{O}_{4}$, just as we observe.

The indices of the fitted reflections indicate the same direction in reciprocal space as those of their nearby fcc $\mathrm{Ni}$ reflections, i.e., the (400) of $\gamma-\mathrm{Al}_{2} \mathrm{O}_{3}$ is just inside (200) of $\mathrm{Ni}$ in Fig. 4(a), indicating that the cubic axes of the two lattices are co-aligned. The underlying structure of $\gamma-\mathrm{Al}_{2} \mathrm{O}_{3}$ is a fcc lattice of $\mathrm{O}^{-2}$ ions with $\mathrm{Al}^{+3}$ ions in interstitial positions. The $\mathrm{O}^{-2}$ lattice constant $(3.95 \AA$ ) is half that of the ordered $\gamma-\mathrm{Al}_{2} \mathrm{O}_{3}$ phase and differs from that of fcc Ni (3.524 $\AA$ ) by only $12 \%$. Apparently the $\gamma$ phase forms in preference to the slightly more stable hexagonal $\alpha$ phase of $\mathrm{Al}_{2} \mathrm{O}_{3}$ 
(i.e., corundum), because of the close lattice matching and a cubic symmetry similar to Ni. Some reflections listed for $\gamma-\mathrm{Al}_{2} \mathrm{O}_{3}$ in Table I were not observed; for instance, a (220) reflection is expected at half the radial distance of the (440) reflection. The (440) reflection is more intense because it is produced by the underlying fcc lattice of $\mathrm{O}^{-2}$, whereas, the (220) reflection is related to the ordering of the $\mathrm{Al}^{+3}$ interstitial ions and the doubled translational unit cell of the ordered $\gamma$ structure with $\mathrm{a}_{0}=7.90 \AA$, and is weaker. Its absence may further reflect incomplete ordering of the $\mathrm{Al}^{+3}$ interstitials, as was suggested for $\gamma-\mathrm{Al}_{2} \mathrm{O}_{3}$ in O-implanted $\mathrm{Al}^{4}$ The third observed spacing in Table I, $2.40 \AA$, potentially fits all three phases fairly well. Although the (113) reflection is not produced from the fcc $\mathrm{O}^{-2}$ structure, it is one of the strongest reflections of $\gamma-\mathrm{Al}_{2} \mathrm{O}_{3}$ and is more likely to be detected. Weak (311) spots are seen in Fig. 4(a), aligned radially with the (311) reflections of $\mathrm{Ni}$ as expected for the precipitate alignment noted above. Diffraction obtained from $\mathrm{Ni}$ samples known to have $\mathrm{NiO}$ precipitates do not show a reflection at this position, confirming its assignment to $\gamma-\mathrm{Al}_{2} \mathrm{O}_{3}$.

Thus all diffraction information indicates that the precipitates formed in $\mathrm{Ni}$ implanted with $\mathrm{O}$ and $\mathrm{Al}$ after annealing are $\gamma-\mathrm{Al}_{2} \mathrm{O}_{3}$. The $\mathrm{NiO}$ precipitates formed after the initial implantation of $\mathrm{O}$ are removed by the $\mathrm{Al}$ implantation and subsequent annealing that produces the more thermodynamically stable $\mathrm{Al}$ oxide. This is also consistent with experiments we performed using $\mathrm{Al}$ and $\mathrm{O}$ implanted at well separated depths that show $\mathrm{O}$ diffusing to the $\mathrm{Al}$ upon annealing, indicating the strong binding of $\mathrm{O}$ and $\mathrm{Al}$. The precipitate size of $\gamma-\mathrm{Al}_{2} \mathrm{O}_{3}$ is more precisely indicated by dark-field images taken in plan view at exact focus such as Fig. 4(b), where particles $\sim 1.5 \mathrm{~nm}$ in diameter are illuminated with the reflections noted in Table I. The small size reflects the dense nucleation of the phase due to the very exothermic reaction of $\mathrm{Al}$ with $\mathrm{O}$.

\section{Results: mechanical properties}

\section{Indentation Results}

The CSM technique for nanoindentation gives both load and stiffness data as function of displacement (depth) in the sample. ${ }^{11}$ Figures 5 and 6 show results from CSM nanoindentation testing and finite-element modeling for two sets of samples, both compared to the untreated $\mathrm{Ni}$ substrate. Figure 5(a) shows the load-displacement data from the $\mathrm{Ni}(\mathrm{O})$ sample before and after the anneal to $550^{\circ} \mathrm{C}$ while Fig. 5(b) show similar results for the dual ion implanted $\mathrm{Ni}(\mathrm{Al}, \mathrm{O})$ sample. The symbols for each curve are the experimentally measured load-displacement curves while the solid lines are the best-fit results of simulating the experiment with the finite-element analysis as 
discussed in the following subsection. In each experiment ten indents were performed at different positions and the results averaged. The standard deviation of the averaged data was generally on the order of the size of the symbols in the figure. The load-displacement data from the untreated substrate is shown in both 5(a) and 5(b) to facilitate comparisons. The corresponding stiffnessdisplacement curves and fits are shown in Fig. 6. As discussed above, the contact stiffness is the observed change in loading force per unit depth while unloading the indenter, and is primarily determined by the elastic properties of the sample.

Examination of the data in Fig. 5 shows that much more force is required to insert the indenter tip to a given depth for either unannealed $\mathrm{Ni}(\mathrm{O})$ or unannealed $\mathrm{Ni}(\mathrm{Al}, \mathrm{O})$ compared to untreated $\mathrm{Ni}$, indicating that the implantation treatments have a dramatic effect on the overall sample hardness. However, the effect of the softer substrate under the treated layers is also immediately evidenced by a change in slope of the load-displacement data. Almost immediately after the start of the measurement, the loading force for either layer rises with depth much faster than for the untreated $\mathrm{Ni}$ until $\sim 50 \mathrm{~nm}$ depth, where the effects of the softer, underlying Ni substrate begin to dominate. At depths beyond $\sim 70 \mathrm{~nm}$ the change in force with depth is essentially parallel to the untreated $\mathrm{Ni}$, but shifted to higher loads. These features indicate that at shallower depths the indentation is more sensitive to the hard surface layer alone while at deeper depths this layer is being pushed into the substrate ahead of the indenter tip and the additional force required is more characteristic of the substrate.

Similarly, the stiffness vs. depth for the implanted samples, shown in Fig. 6, has a different behavior near the surface and at depths beyond $50 \mathrm{~nm}$. However, the stiffness of the implanted samples is only slightly higher than the unimplanted Ni near the surface and then falls well below it at greater depths. This effect can be understood by considering the area in contact with the diamond tip when indenting a hard layer on a soft substrate. As the layer is pressed into the substrate with increasing load, the area in contact with the tip is smaller than it would be when indenting Ni alone; since stiffness is proportional to the square root of the area of contact as well as to the elastic moduli, ${ }^{20}$ the observed stiffness is lower. Indeed, the finite-element modeling we use for analysis of this data infers values for Young's modulus in the implanted layers which are somewhat higher than that for the underlying $\mathrm{Ni}$, but correctly predicts that the stiffness measured at deeper depths in the implanted samples is lower than measured for pure $\mathrm{Ni}$. 


\section{Finite Element Modeling}

As discussed above, the values of yield strength and Young's elastic modulus for the implanted layers were deduced using finite-element simulations to fit the nanoindentation data. ${ }^{20}$ The material in the implanted layers was modeled as elastic-plastic with no work hardening, as appears appropriate for highly ion-damaged Ni. The work hardening rate for the Ni substrate was fixed at $0.65 \mathrm{GPa}$, taken from the literature. ${ }^{25}$ The Poisson's ratio $(0.312)$ of pure Ni was used for both the implanted layers and the underlying Ni substrate. The increased yield strength and elastic modulus in the implanted regions were each modeled by a step-wise approximation to a Gaussian profile, each with the same width. The two peak amplitudes and the single gaussian profile width were varied in trial simulations until agreement with the experiment was obtained at all indentation depths. This approach assumes that any enhancement of yield strength or Young's modulus is approximately Gaussian in depth dependence, similar to the implanted atom concentrations and the lattice damage produced by the implantation process.

The yield strength profile deduced for the annealed $\mathrm{Ni}(\mathrm{Al}, \mathrm{O})$ sample is shown in Fig. 1 as a solid line. Again, the optimum width of the strength profile was deduced by a series of simulations with different profile widths; the $255 \mathrm{~nm}$ half-width shown in Fig. 1 gave the best fit to both force and stiffness data over all sampled depths. The fact that the deduced strength profile is $\sim 25 \%$ wider than the concentration profile is consistent with precipitate strengthening; the reciprocal of interparticle spacing goes as the cube root of volume fraction for constant particle size, so the strength enhancement would extend well into the tail of the concentration profile. In fact, the cube root of a true Gaussian profile is another Gaussian 1.7 times wider. Recall as well that the measured concentration profile and its depth scale are somewhat uncertain due to limitations in ion-beam profiling for these light elements, as discussed above.

Finite-element modeling of samples such as these, whose properties vary with depth, is of course more uncertain than modeling a simple uniform layer, but a careful choice of the layer profile combined with examination of the fit to both force and stiffness over all depths can minimize the added uncertainty. ${ }^{18-20}$ In particular, the additional stiffness vs. displacement information afforded by the CSM technique makes the modeling far more sensitive to the details of the depth profile and, for example, allows the overall width of the affected layer to be determined by the fitting to within $20-40 \mathrm{~nm}$.

Annealed, unimplanted $\mathrm{Ni}$ was indented and modeled separately to verify its properties, showing a region near the surface with increased hardness ( $Y=0.40 \mathrm{GPa}$ ), but with the underlying material at the published yield strength of $0.15 \mathrm{GPa}^{27}$ The Young's modulus for the Ni at all depths 
was found to be $204 \mathrm{GPa}$, in good agreement with published values. ${ }^{27}$ We have observed an increased hardness near the surface of pure $\mathrm{Ni}$ before ${ }^{18}$, and tentatively ascribe it to delayed formation of dislocations. The material is well-annealed, so work-hardening due to polishing is unlikely, while the hardening extends to too great a depth to be consistent with a hard surface layer such as an oxide. Although including this modest increase in substrate yield strength has little effect on the values deduced for the surface layer, it was included for completeness by using the yield strength profile determined for the untreated $\mathrm{Ni}$ in the underlying substrate. That is, the model substrate at depths below each implanted layer was given the strength profile determined earlier for pure Ni at those depths.

The best-fit simulated load-displacement curves are shown as solid lines in Fig. 5 for each sample, with the corresponding stiffness-displacement curves in Fig. 6. In each case the layer yield strength and Young's modulus were varied until the simulated data matched the experiment well at all sampled depths. The profile shape and width shown in Fig. 1 was found to be best for all samples except the untreated $\mathrm{Ni}$ and the annealed $\mathrm{Ni}(\mathrm{O})$; the untreated $\mathrm{Ni}$ was modeled as discussed above, with a slightly harder surface, decaying exponentially with depth to $0.15 \mathrm{GPa}$ at $1 \mu \mathrm{m}$. The annealed $\mathrm{Ni}(\mathrm{O})$ simulations fit best using a profile of $285 \mathrm{~nm}$ half-width without any reduction at the surface; i.e., a constant level of $\mathrm{Y}$ and $\mathrm{E}$ from the surface to half way through the layer. For both implanted samples and the untreated $\mathrm{Ni}$ in Figs. 5 and 6, the simulations are seen to match the CSM experiment very well.

Table II gives a summary of the peak values of $\mathrm{Y}$ and $\mathrm{E}$ deduced for each of the samples, as well as the full width at half maximum of the profile which gave the best fit. Young's elastic modulus in the as-implanted layers remained comparable to that of untreated $\mathrm{Ni}$, increasing from about 200 to $260-280 \mathrm{GPa}$. Yield strength was more substantially affected, increasing from about $0.15 \mathrm{GPa}$ for untreated $\mathrm{Ni}$ to near $5 \mathrm{GPa}$ for the hardest precipitate-containing layers. The peak values of $\mathrm{Y}$ and $\mathrm{E}$ deduced for the unannealed $\mathrm{Ni}(\mathrm{O})$ and $\mathrm{Ni}(\mathrm{Al}, \mathrm{O})$ layers were essentially identical at $4.61 \mathrm{GPa}$ and $258 \mathrm{GPa}$, and $4.60 \mathrm{GPa}$ and $277 \mathrm{GPa}$, respectively. After annealing to $550^{\circ} \mathrm{C}$, on the other hand, the $\mathrm{Ni}(\mathrm{O})$ sample is reduced to $1.15 \mathrm{GPa}$ and $233 \mathrm{GPa}$, while the $\mathrm{Ni}(\mathrm{A} 1, \mathrm{O})$ sample still maintains much of the benefit at $4.17 \mathrm{GPa}$ and $291 \mathrm{GPa}$.

Also shown in Table II are the results obtained from $\mathrm{Ni}$ implanted with $\mathrm{Al}$ alone, before and after the $550^{\circ} \mathrm{C}$ anneal. The $\mathrm{Ni}(\mathrm{Al})$ sample exhibits a modest increase in yield strength to $\sim 2.5 \mathrm{GPa}$, with the anneal having little effect. Previous work ${ }^{8}$ had shown that Al-implanted Ni forms an fcc solution for up to 30 at. $\% \mathrm{Al}$, so we have not examined the microstructure here. We attribute the 
increase in yield strength to a combination of solution strengthening and work hardening produced by implantation damage.

The hardnesses which are shown in Table II for the treated layers are calculated "intrinsic" hardnesses for each layer, determined by a separate calculation as discussed earlier. After a good fit to each experimental measurement was established, an additional computer simulation using the peak yield strength and modulus of the layer for a hypothetical bulk "sample" was then used to deduce the intrinsic hardness of the layer material alone. An example of such a calculation is shown in Fig, 7. The solid line shows the calculated hardness vs. displacement from a simulation of a "bulk" sample of the annealed $\mathrm{Ni}(\mathrm{Al}, \mathrm{O})$ material. The value at depth asymptotically approaches a peak hardness of $12.2 \pm 1.2 \mathrm{GPa}$. The other two curves in Fig. 7 are hardness vs. displacement values derived directly from CSM data using the standard "Oliver-Pharr" analysis. ${ }^{11,12}$ The curve using solid symbols is the hardness obtained from the untreated, bulk Ni. The open symbols are the Oliver-Pharr analysis of the raw data from the annealed $\mathrm{Ni}(\mathrm{Al}, \mathrm{O})$ sample. Although the hardness calculated by this conventional approach rises to $10 \mathrm{GPa}$ at $40 \mathrm{~nm}$, the rapid fall-off with depth shows the effect of the substrate on the conventional analysis and further illustrates the importance of a modeling-based analysis for such thin layers.

Finally, Fig. 8 show a scanning electron micrograph of the residual impression left in the $\mathrm{Ni}(\mathrm{Al}, \mathrm{O})$ surface after a deep indentation to several micrometers. This indent serves to qualitatively test the ductility of the ion-treated layer, since it penetrated well through the treated surface layer and into the underlying $\mathrm{Ni}$ substrate. Careful examination of this and other deep indents revealed no sign of layer cracking or de-adhesion from the underlying substrate, showing that even though the surface layer is much harder than the substrate, it has retained the ductility expected for a metal. Good adhesion to the substrate is often an attribute of implanted metal layers since the implanted profile tails into the substrate without an abrupt interface.

\section{Discussion}

Our observations can be summarized as follows. Room temperature ion implantation of $\mathrm{O}$ into $\mathrm{Ni}$ to a concentration level of $\sim 10$ at. \% results in the formation of a fine dispersion of $\mathrm{NiO}$ precipitates $1.5-3.5 \mathrm{~nm}$ in diameter. These precipitates increase the yield strength in the treated zone to near $5 \mathrm{GPa}$, an increase of more than $30 \mathrm{X}$ over pure bulk Ni. A subsequent ion implantation of $\mathrm{Al}$ to a similar concentration over approximately the same depth converts many, but not all, of the $\mathrm{NiO}$ precipitates to either $\mathrm{NiAl}_{2} \mathrm{O}_{4}$ or $\gamma-\mathrm{Al}_{2} \mathrm{O}_{3}$ precipitates, and leaves the yield strength essentially unchanged. Annealing the $\mathrm{O}$-only $\mathrm{Ni}(\mathrm{O})$ sample at $550^{\circ} \mathrm{C}$ for 2 hours ripens the $\mathrm{NiO}$ precipitates to 
$7-20 \mathrm{~nm}$ in diameter, with the depth profile of the $\mathrm{O}$ nearly unchanged. The substantial increase of precipitate size reduces the yield strength to $\sim 1 \mathrm{GPa}$, which is still six times that of bulk Ni. The same $550^{\circ} \mathrm{C}$ anneal applied to the dual-implant $\mathrm{Ni}(\mathrm{Al}, \mathrm{O})$ sample converts all of the precipitates to the $\gamma-\mathrm{Al}_{2} \mathrm{O}_{3}$ phase, with a more uniform size distribution of $1-2 \mathrm{~nm}$ in diameter. The yield strength after annealing the $\mathrm{Ni}(\mathrm{Al}, \mathrm{O})$ sample is still over $4 \mathrm{GPa}$, substantially higher than for the annealed $\mathrm{Ni}(\mathrm{O})$ sample.

To understand the extraordinary strengths that we have achieved with these treatments, we turned to dispersion-hardening theory. ${ }^{1}$ This theory describes the strengthening which results from the inhibition of plastic flow in a metal due to pinning of dislocations by hard particles. To first order, the strengthening is predicted to scale with the reciprocal of particle spacing. In the case of spherical particles, one has more specifically for the resulting shear-stress increment

$$
\Delta \tau=0.84\left(\frac{G b}{2 \pi \lambda(1-v)^{1 / 2}}\right) \ln \frac{d}{b} \quad \text { Eq. } 1
$$

where $d$ is the particle diameter, $\lambda$ is the interparticle spacing (edge-to-edge), $v$ is Poisson's ratio, $G$ is the shear modulus, and $\mathrm{b}$ is the Burger's vector for $\mathrm{Ni}(0.279 \mathrm{~nm})$. The values predicted by this equation for our observed microstructures are shown in Table II and the results are plotted in Fig. 9. Only the three samples with either $\mathrm{NiO}$ or $\gamma-\mathrm{Al}_{2} \mathrm{O}_{3}$ precipitates were evaluated; numbers for the asimplanted $\mathrm{Ni}(\mathrm{Al}, \mathrm{O})$ sample were not evaluated due to uncertainties about the mixture of two oxide phases. These numbers were obtained using $\mathrm{G}=77.8 \mathrm{GPa}$ and $v=0.312$ obtained from a Ruess orientational average of compliances for $\mathrm{Ni}$, as discussed elsewhere. ${ }^{28}$ For each sample the measured $\mathrm{O}$ concentration was used with the known oxide densities to obtain an estimate of the precipitate volume fraction. This was then used with the measured particle sizes and an assumed close-packed fcc array of precipitates to estimate the interparticle spacing $\lambda$. The figure plots the predicted increment of yield stress vs. our observed values, as well as similar results found by us in earlier work with precipitate strengthening of $\mathrm{Al}$ by $\mathrm{O}$ implantation. ${ }^{2-5}$

In comparing the observed strengths to the theory, we have neglected two things. First, we have assumed that the experimentally observed strengthening is primarily due to the precipitates, neglecting the contributions of solution strengthening due to excess $\mathrm{Al}$ in the layer and to work hardening due to implantation damage. Both of these effects are estimated to be smaller than the precipitate strengthening, primarily based on our observations of Al-implanted Ni. Since there is much less excess $\mathrm{Al}$ in the dual implant sample than in the Al-only sample, the contribution of solution strengthening by $\mathrm{Al}$ is expected to be no more than $20 \%$ of the total strength. Additionally, 
preliminary results from $\mathrm{Ni}$-implanted $\mathrm{Ni}$ show only modest strengthening from implantation damage at similar levels of displacements per atom. Since it is not clear how such disparate strengthening mechanisms might add, we have not attempted to factor out the separate contributions.

The second consideration in comparing these strengths to the theory is that we have neglected a factor in the theory due to orientational averaging which has been estimated to be perhaps as large as 2 or 3 (i.e., the predicted values of the shear-stress increment should be increased by this factor). ${ }^{1,29}$ This arises because the $\Delta \tau$ in Eq. 1 represents the projection of applied shear stress onto the dislocation glide plane, so that for random relative orientations of grains and shear stress, $\Delta \tau$ is smaller than the applied shear stress. However, the important point is that we observe good semiquantitative agreement in absolute magnitude, and that the variations between samples agree very well for a wide range of microstructures, different precipitate types and sizes, and for two very different fcc metals with shear stresses differing by a factor of 3 .

\section{Summary}

Ion implantation provides a means of producing microstructures that may be inaccessible by more conventional metallurgy, in this case producing much higher precipitate densities and smaller sizes than are normally practical. We used $\mathrm{O}$ and $\mathrm{Al}$ implantation to produce these very fine precipitate microstructures and then measured the resulting strengths using nanoindentation. The indentation data were analyzed by using detailed finite-element modeling to understand the combined response of the hardened layers and the much softer substrate, allowing the intrinsic elastic and plastic properties of the precipitate-containing layers to be separated from those of the substrate. The resulting microstructures contained $\mathrm{NiO}$ or $\gamma-\mathrm{Al}_{2} \mathrm{O}_{3}$ precipitates (or a mixture, possibly with $\mathrm{NiAl}_{2} \mathrm{O}_{4}$ ) at sizes ranging from 7-20 nm for annealed $\mathrm{Ni}(\mathrm{O})$ down to 1-2 $\mathrm{nm}$ for annealed $\mathrm{Ni}(\mathrm{Al}, \mathrm{O})$, and precipitate densities up to $\sim 5 \times 10^{19} \mathrm{~cm}^{-3}$. The observed yield strengths were near $5 \mathrm{GPa}$ for the hardest layers and are in reasonable agreement with the predictions of precipitate hardening theory. The high yield strengths are comparable to those previously reported by us for amorphous $\mathrm{Ni}(\mathrm{Ti}, \mathrm{C})$, where the very different hardening mechanism of structural disorder is operational, augmented by $\mathrm{Ti}-\mathrm{C}$ atomic pairing. ${ }^{17,18}$ The present work is significant in three respects: first, it establishes the validity of dispersion-strengthening theory in an important new regime; second, it demonstrates that properly tailored microstructures can strengthen $\mathrm{Ni}$ to new levels; and, third, it shows that ion-beam treatments provide a promising approach to hardening of Ni surfaces. 


\section{Acknowledgements}

Technical assistance by M. P. Moran and K. G. Minor is gratefully acknowledged. Careful indentation measurements by Barry Lucas and co-workers at the Nano Instruments Innovation Center of MKS Systems Corp. are appreciated. Sandia is a multiprogram laboratory operated by Sandia Corporation, a Lockheed Martin Company, for the US Department of Energy, and this work was supported by their Office of Basic Energy Sciences under contract DE-AC04-94AL85000. 


\section{Tables}

Table I. Lattice Spacings for Phases in Ni Implanted with O and Al.

\begin{tabular}{|l|l|l|l|}
\hline $\mathbf{N i O}^{2}$ & $\mathbf{N i A l}_{2} \mathbf{O}_{4}{ }^{{ }^{\mathbf{b}}}$ & $\gamma-\mathbf{A l}_{2} \mathbf{O}_{3}{ }^{{ }^{\mathbf{}}}$ & Ni(Al,0) observed ${ }^{\mathbf{d}}$ \\
\hline & $4.65 \AA(111)$ & $4.56 \AA(111)$ & \\
\hline & $2.846 \AA(220)$ & $2.80 \AA(220)$ & \\
\hline $2.41 \AA(111)$ & $2.427 \AA(311)$ & $2.39 \AA(311)$ & $2.40 \pm 0.015 \AA$ \\
\hline & & $2.28 \AA(222)$ & \\
\hline $1.476 \AA(220)$ & $1.423 \AA(440)$ & $1.977 \AA(400)$ & $1.975 \pm 0.01 \AA$ \\
\hline
\end{tabular}

${ }^{\mathrm{a}}$ Face-centered cubic phase, NaCl-type, $\mathrm{a}_{0}=4.177 \AA$. ICCD PDF card \#04-0835. ${ }^{26}$

${ }^{b}$ Cubic spinel phase, $a_{0}=8.048 \AA$. ICCD PDF card \#10-0339. ${ }^{26}$

${ }^{c}$ Cubic phase, closely related to spinel structures, $a_{0}=7.90 \AA$. ICCD PDF card \#10-0425. ${ }^{26}$

${ }^{d}$ Observed in $\mathrm{Ni}$ implanted with $\mathrm{Al}$ and $\mathrm{O}$ after annealing 2 hours at $550^{\circ} \mathrm{C}$.

Table II. Mechanical properties determined by nanoindentation and finite-element modeling.

\begin{tabular}{|c|c|c|c|c|c|c|}
\hline Material & Yield strength & $\begin{array}{c}\text { Young's elastic } \\
\text { modulus }\end{array}$ & Hardness & $\begin{array}{l}\text { Profile } \\
\text { width }\end{array}$ & $\begin{array}{l}\text { Precipitate } \\
\text { size range }\end{array}$ & $\begin{array}{l}\text { Theoretical } \\
\text { Yield strength }\end{array}$ \\
\hline Untreated $\mathbf{N i}$ & $0.15 \mathrm{GPa}^{\mathrm{a}}$ & $204 \pm 11 \mathrm{GPa}$ & $1.1 \pm 0.3 \mathrm{GPa}^{\mathrm{a}}$ & na & -- & -- \\
\hline $\mathrm{Ni}(\mathrm{O})$ - as implanted & $4.61 \pm 0.49 \mathrm{GPa}$ & $258 \pm 20 \mathrm{GPa}$ & $12.9 \pm 1.4 \mathrm{GPa}$ & $255 \mathrm{~nm}$ & $1.5-3.5 \mathrm{~nm}$ & $4.44 \pm 1.0 \mathrm{GPa}$ \\
\hline $\mathrm{Ni}(\mathrm{O})-550^{\circ} \mathrm{C}$ & $1.15 \pm 0.12 \mathrm{GPa}$ & $233 \pm 21 \mathrm{GPa}$ & $3.8 \pm 0.4 \mathrm{GPa}$ & $285 \mathrm{~nm}$ & $7-20 \mathrm{~nm}$ & $0.93 \pm 0.3 \mathrm{GPa}$ \\
\hline $\begin{array}{l}\mathrm{Ni}(\mathrm{Al}, \mathrm{O}) \text { - as } \\
\text { implanted }\end{array}$ & $4.60 \pm 0.52 \mathrm{GPa}$ & $277 \pm 24 \mathrm{GPa}$ & $13.1 \pm 1.6 \mathrm{GPa}$ & $255 \mathrm{~nm}$ & $b$ & $b$ \\
\hline $\mathrm{Ni}(\mathrm{Al}, \mathrm{O})-550^{\circ} \mathrm{C}$ & $4.17 \pm 0.3 \mathrm{GPa}$ & $291 \pm 26 \mathrm{GPa}$ & $12.2 \pm 1.2 \mathrm{GPa}$ & $255 \mathrm{~nm}$ & $1-2 \mathrm{~nm}$ & $4.21 \pm 0.6 \mathrm{GPa}$ \\
\hline $\mathrm{Ni}(\mathrm{Al})$ - as implanted & $2.54 \pm 0.11 \mathrm{GPa}$ & $275 \pm 25 \mathrm{GPa}$ & $8.0 \pm 0.6 \mathrm{GPa}$ & $225 \mathrm{~nm}$ & -- & -- \\
\hline $\mathrm{Ni}(\mathrm{Al})-\mathbf{5 5 0}^{\circ} \mathrm{C}$ & $2.46 \pm 0.5 \mathrm{GPa}$ & $250 \pm 26 \mathrm{GPa}$ & $7.7 \pm 1.2 \mathrm{GPa}$ & $240 \mathrm{~nm}$ & -- & -- \\
\hline
\end{tabular}

${ }^{a}$ Yield strength for $\mathrm{Ni}$ in the bulk. A near-surface value of $0.4 \pm 0.02 \mathrm{GPa}$ was measured here,

tailing exponentially to $0.15 \mathrm{GPa}$ at $1 \mu \mathrm{m}$. Hardness was calculated using the bulk yield strength.

${ }^{\mathrm{b}}$ Implanted region has a mixture of $\mathrm{NiO}$ and $\gamma-\mathrm{Al}_{2} \mathrm{O}_{3}$ or $\mathrm{NiAl}_{2} \mathrm{O}_{4}$ precipitates. 


\section{Figure captions}

Fig. 1. Concentration profiles of $\mathrm{O}$ and $\mathrm{Al}$ in $\mathrm{Ni}$ after implantation and an anneal at $550^{\circ} \mathrm{C}$ for 2 hours. Dashed line is Al, dash-dot line is $\mathrm{O}$, with scale on the left. The solid line is the yield strength profile deduced from a best-fit simulation of nanoindentation data from this sample, with the scale on the right.

Fig. 2. Plan-view transmission electron microscopy of $\mathrm{Ni}$ implanted with O. (a) Diffraction pattern from unannealed sample. (b) Dark-field micrograph showing NiO precipitates in unannealed sample. (c) Dark-field micrograph showing NiO precipitates in $550^{\circ} \mathrm{C}$ annealed sample.

Fig. 3. Cross-section, bright-field transmission electron micrographs of $\mathrm{Ni}$ implanted with $\mathrm{O}$ and $\mathrm{Al}$, (a) unannealed, and (b) after $550^{\circ} \mathrm{C}$ anneal. Both micrographs were taken in an underfocussed condition to enhance precipitate contrast.

Fig. 4. Plan-view transmission electron microscopy of $\mathrm{Ni}$ implanted with $\mathrm{O}$ and $\mathrm{Al}$, annealed at $550^{\circ} \mathrm{C}$. (a) Diffraction pattern. (b) Dark-field micrograph showing $\gamma-\mathrm{Al}_{2} \mathrm{O}_{3}$ precipitates.

Fig. 5. Indentation load-displacement curves for (a) O-implanted $\mathrm{Ni}$, before and after anneal, and (b) $\mathrm{O}+\mathrm{Al}$ implanted $\mathrm{Ni}$, before and after anneal. Symbols are experimental load-displacement values, while the solid lines are obtained from finite-element simulations.

Fig. 6. Indentation stiffness-displacement curves for (a) O-implanted $\mathrm{Ni}$, before and after anneal, and (b) $\mathrm{O}+\mathrm{Al}$ implanted $\mathrm{Ni}$, before and after anneal. Symbols are experimental stiffnessdisplacement values, while the solid lines are obtained from finite-element simulations.

Fig. 7. Hardness vs. displacement. The triangles and circle symbols are from a conventional OliverPharr analysis of the nanoindentation data from untreated $\mathrm{Ni}$ and from the $\mathrm{O}+\mathrm{Al}$ implanted $\mathrm{Ni}$. The solid line is a calculated hardness vs. depth for the simulation of a hypothetical bulk sample with the same properties as the $\mathrm{Ni}(\mathrm{Al}, \mathrm{O})$ layer, with a bulk hardness at depth of $12.2 \mathrm{GPa}$.

Fig. 8. Secondary electron microscopy image of a portion of a deep indent in the Ni(A1,O) sample.

Fig. 9. Measured yield strengths vs. shear-stress increments calculated from dispersion-hardening theory. Open symbols are from the present work, while the solid symbols are from previous work with O-implanted $\mathrm{Al}^{2-5}$ 


\section{References}

1. R. J. Bourcier, S. M. Myers and D. H. Polonis, Nucl. Instr. \& Meth. B44 (1990) 278, and citations therein.

2. R. J. Bourcier, S. M. Myers and D. H. Polonis, ibid.

3. R. J. Bourcier, D. M. Follstaedt, M. T. Dugger and S. M. Myers, Nucl. Instr. \& Meth. B59/60 (1991) 905.

4. D. M. Follstaedt, S. M. Myers and R. J. Bourcier, Nucl. Instr. \& Meth. B59/60 (1991) 909.

5. D. M. Follstaedt, S. M. Myers, R. J. Bourcier and M. T. Dugger, Proc. of the Int. Conf. on Beam Processing of Advanced Materials, 11/2-5/92 (1993) 507.

6. The ion ranges and number of atomic displacements were calculated using the Monte Carlo code described by J. F. Ziegler, J. P. Biersack, and U. Littmark, The Stopping and Range of Ions in Solids (Pergamon, New York, 1985); the employed version was TRIM-90, provided by J. F. Ziegler (private communication).

7. SIMNRA User's Guide, Technical Report IPP 9/113 (Max-Planck-Institut für Plasmaphysik, Garching, Germany, 1997).

8. M. Ahmed and D. I. Potter, Act. Met. 33 (1985) 2221.

9. J. B. Pethica, R. Hutchings and W. C. Oliver, Phil. Mag. A, 48 (1983) 593.

10. M. F. Doerner and W. D. Nix, J. Mater. Res. 1 (1986) 601.

11. W. C. Oliver and G. M. Pharr, J. Mater. Res. 7 (1992) 1564.

12. G. M. Pharr and W. C. Oliver, MRS Bull. 17 (1992) 28.

13. All of the indentation tests were performed at the Nano Instruments Innovation Center of MTS Systems Corp., Knoxville, TN.

14. J. A. Knapp and D. M. Follstaedt, Mat. Res. Soc. Symp. Proc. 397 (1996) 387.

15. J. A. Knapp, D. M. Follstaedt, J. C. Barbour and S. M. Myers, Nucl. Instr. Meth. B127/128 (1997) 935.

16. J. A. Knapp, D. M. Follstaedt, J. C. Barbour and S. M. Myers, J. W. Ager III, O. R. Monteiro, and I. G. Brown, Mat. Res. Soc. Symp. Proc. 438 (1997) 617.

17. S. M. Myers, D. M. Follstaedt, J. A. Knapp and T. A. Christenson, Mat. Res. Soc. Symp. Proc. 444 (1997) 99.

18. S. M. Myers, J. A. Knapp, D. M. Follstaedt and M. T. Dugger, J. App. Phys. 83 (1998) 1256. 
19. J. A. Knapp, D. M. Follstaedt, S. M. Myers, J. C. Barbour, T. A. Friedmann, J. W. Ager III, O. R. Monteiro, and I. G. Brown, Surf. Coat. Technol. 103-104 (1998) 268.

20. J. A. Knapp, D. M. Follstaedt, S. M. Myers, J. C. Barbour and T. A. Friedmann, J. App. Phys. 85 (1999) 1460.

21. ABAQUS version 5.7, Hibbitt, Karlsson \& Sorensen, Inc., Pawtucket, RI.

22. R. A. Swalin and A. Martin, Tran. AIME 206 (1956) 567.

23. W. Gust, M. B. Hintz, A. Lodding, H. Odelius, and B. Prendel, Phys. Stat. Sol. A 64 (1981) 187.

24. J.-W. Park and C. J. Altstetter, Metall. Trans. A 18 (1987) 43.

25. Atlas of Stress-Strain Curves, edited by H. E. Boyer (ASM, Metals Park, Ohio, 1987), p. 551.

26. International Center for Diffraction Data, Newtown Square, PA.

27. Metals Handbook (ASM, Metals Park, Ohio, 1990), Vol. 2, pp. 437, 1143.

28. J. P. Hirth and J. Lothe, Theory of Dislocations (Krieger Publishing, Malabar, Florida, 1992), pp. 426-428, 836.

29. Introduction to Dislocations, edited by D. Hull and D. J. Bacon, third edition (Pergamon Press, New York, 1984), p. 248. 


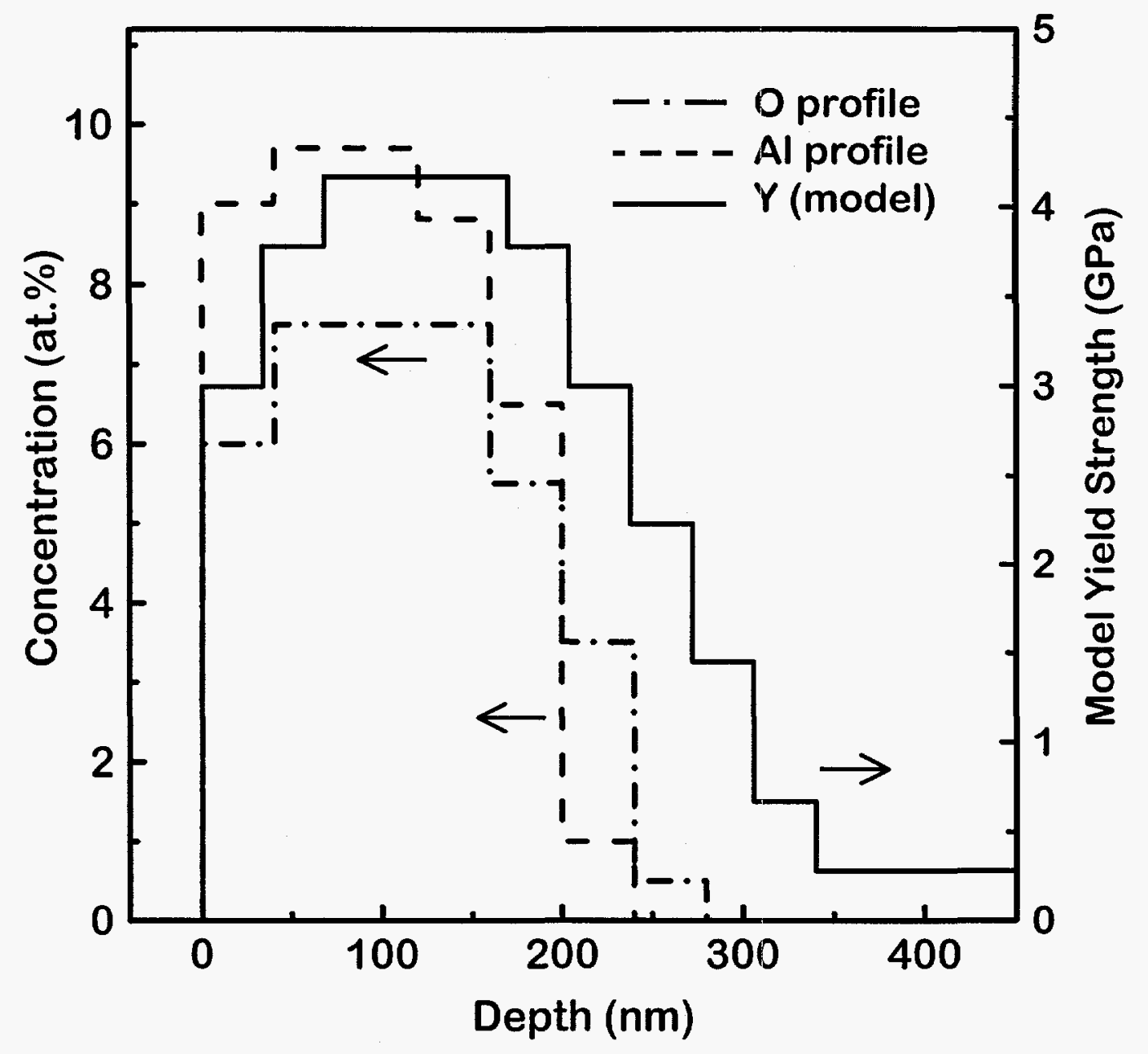

Figure 1 
(a)

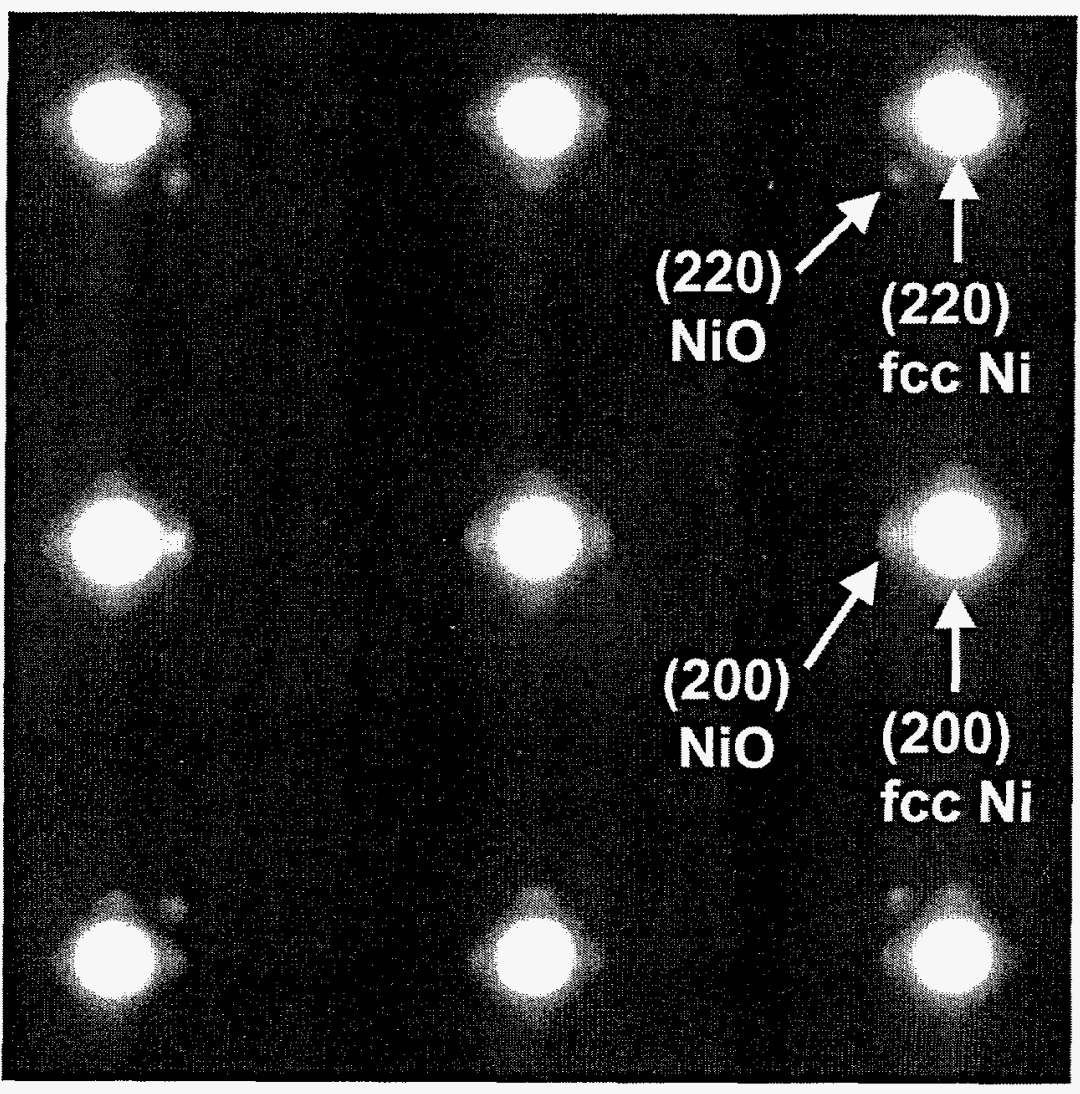

(b)

(c)
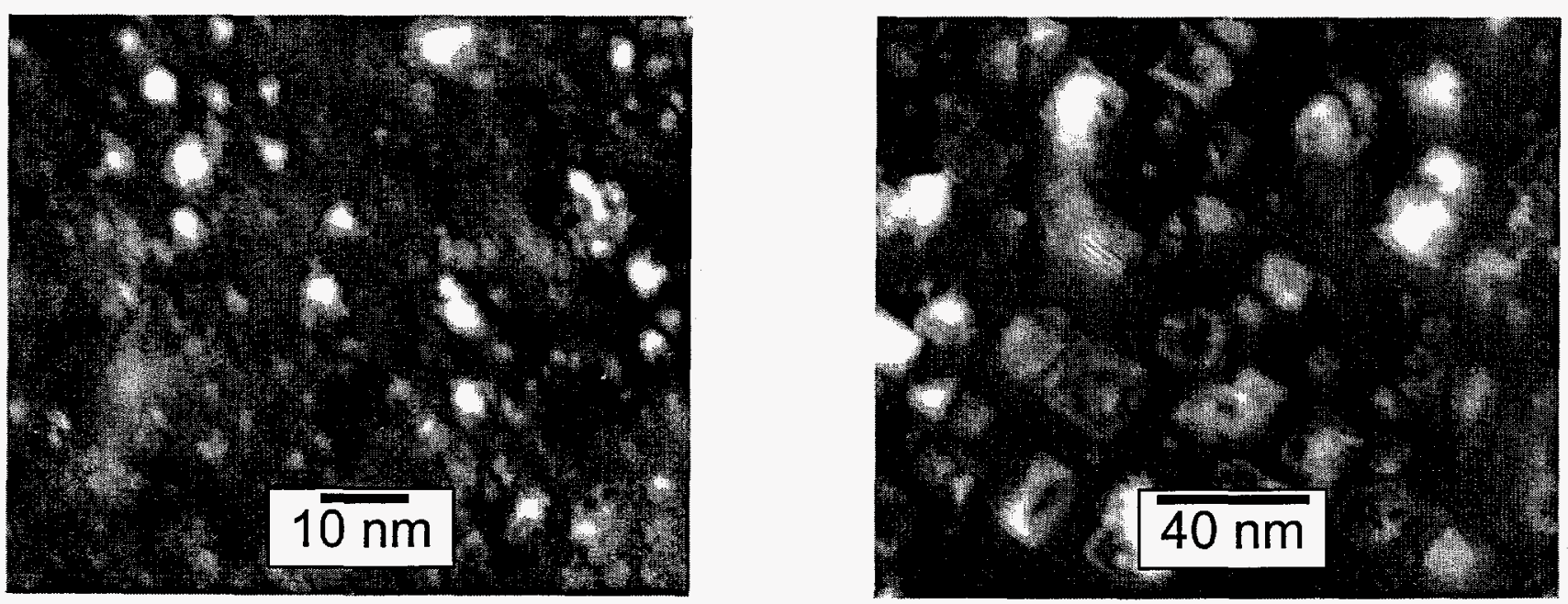

Figure 2 
(a)

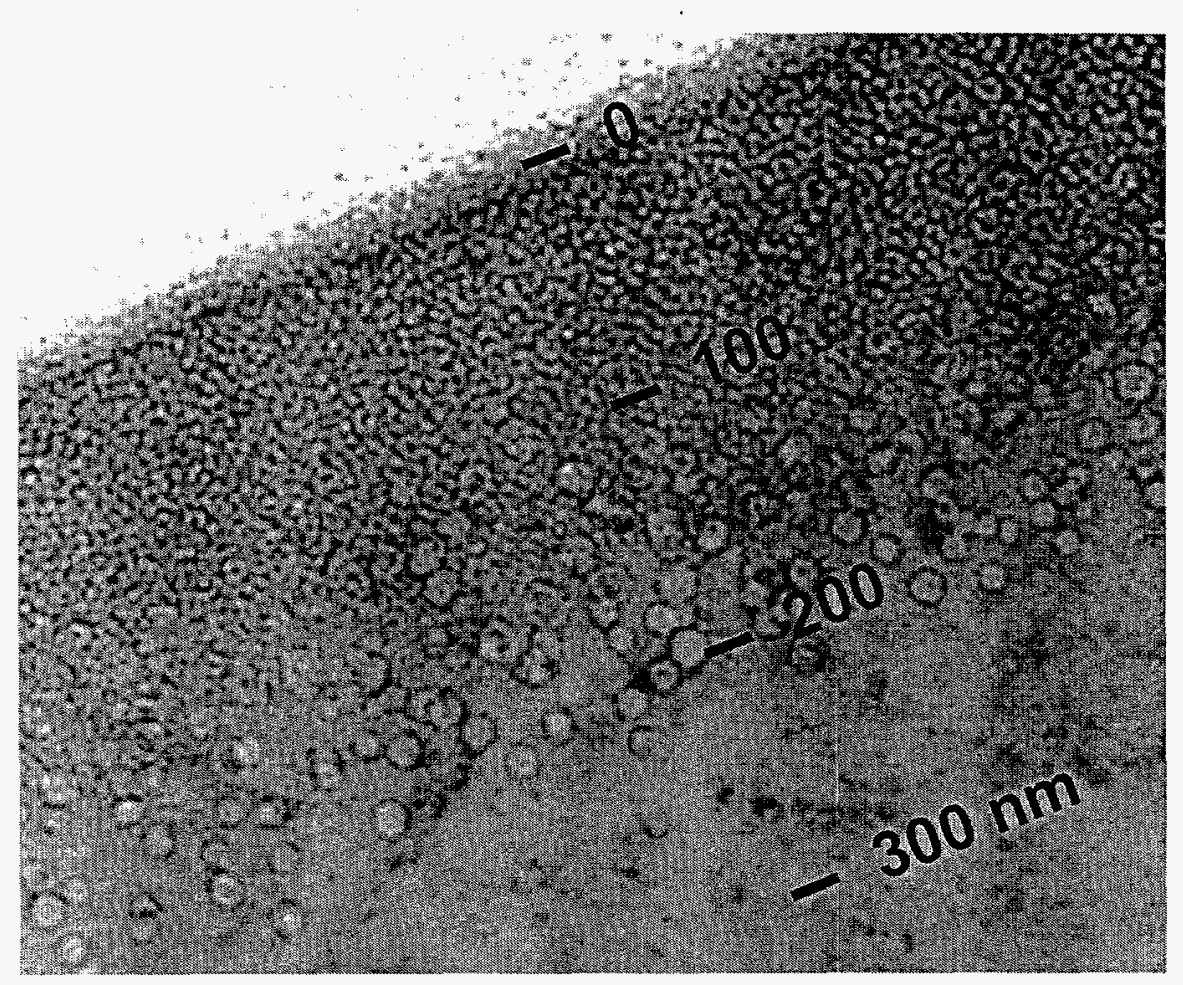

(b)

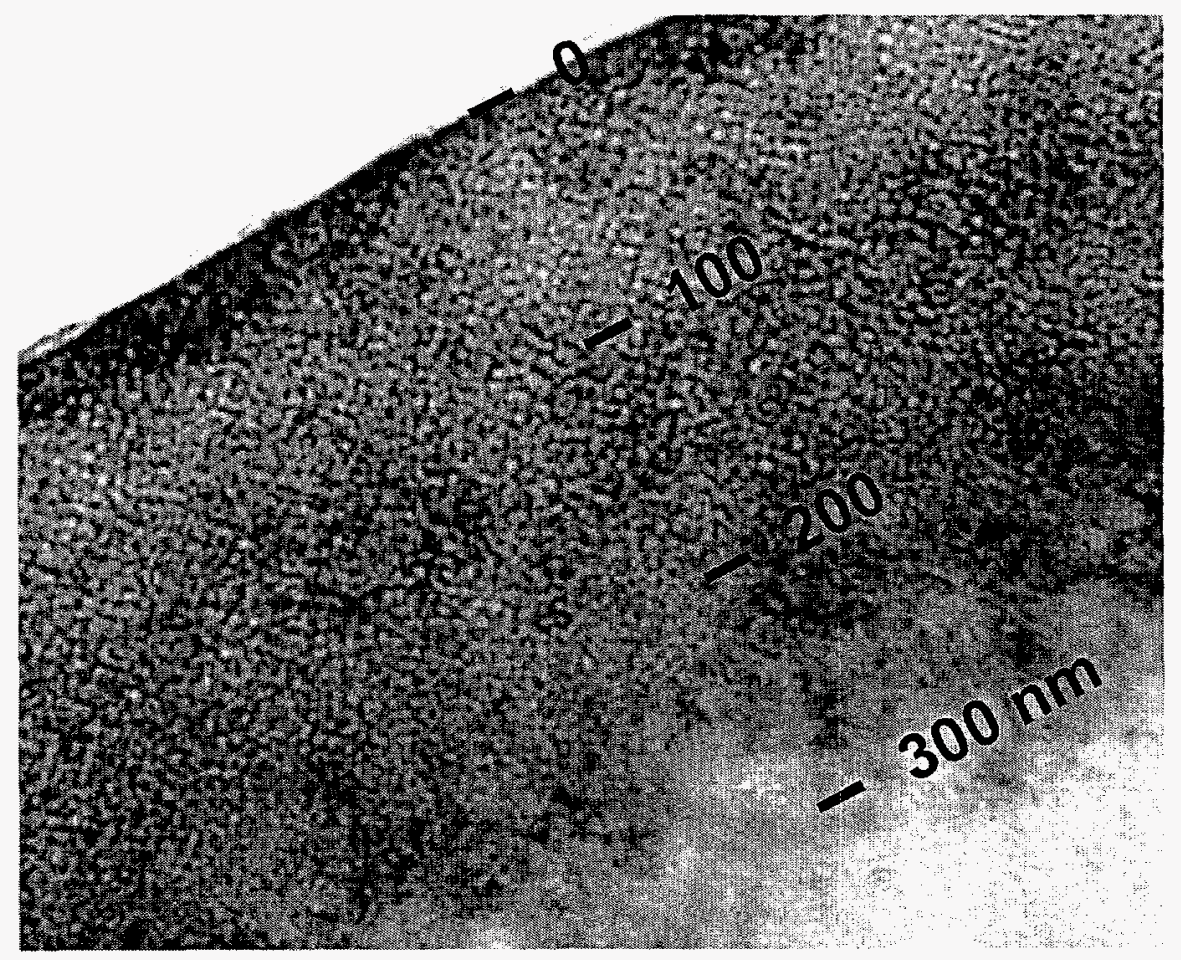

Figure 3 
(a)

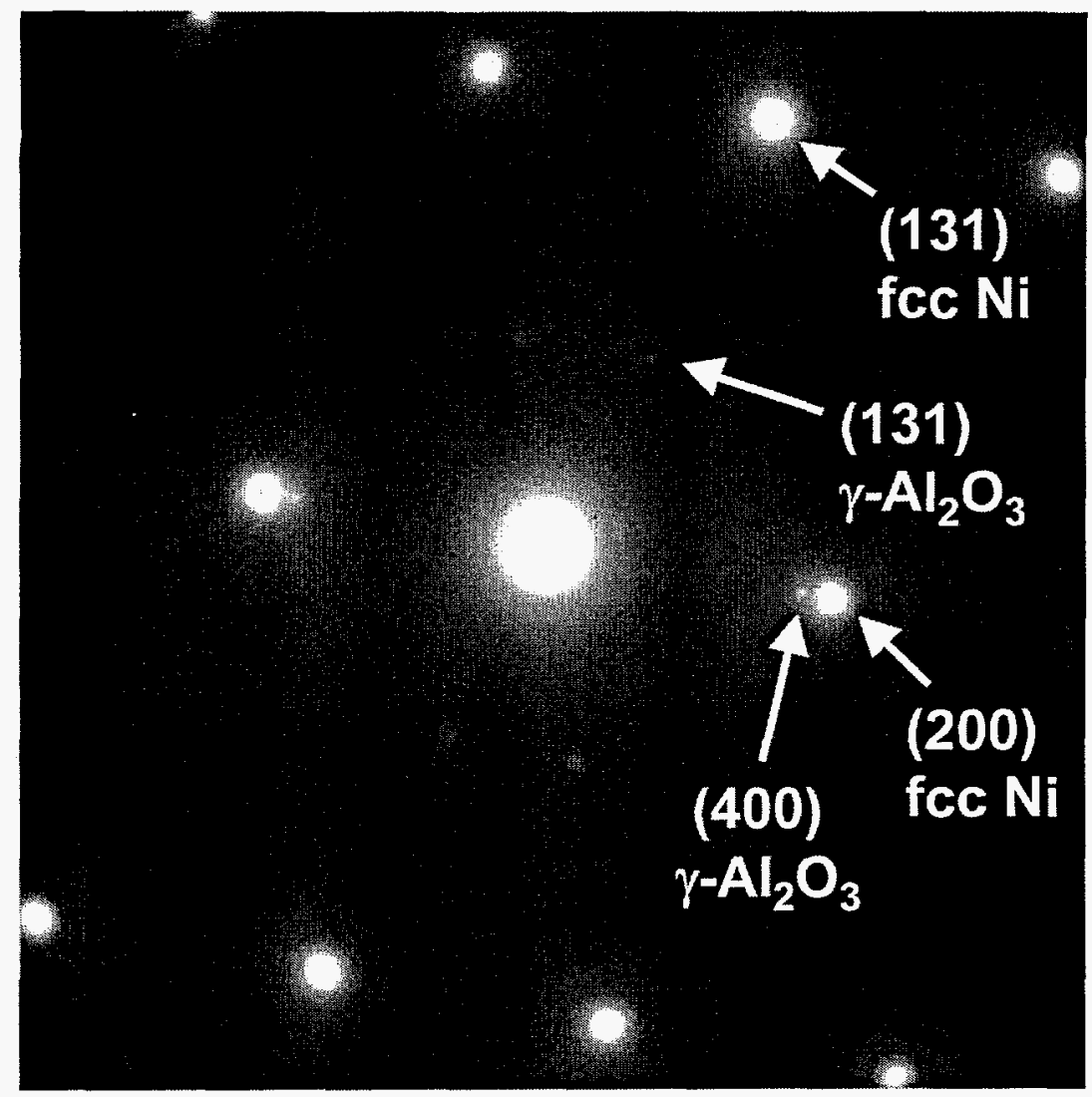

(b)

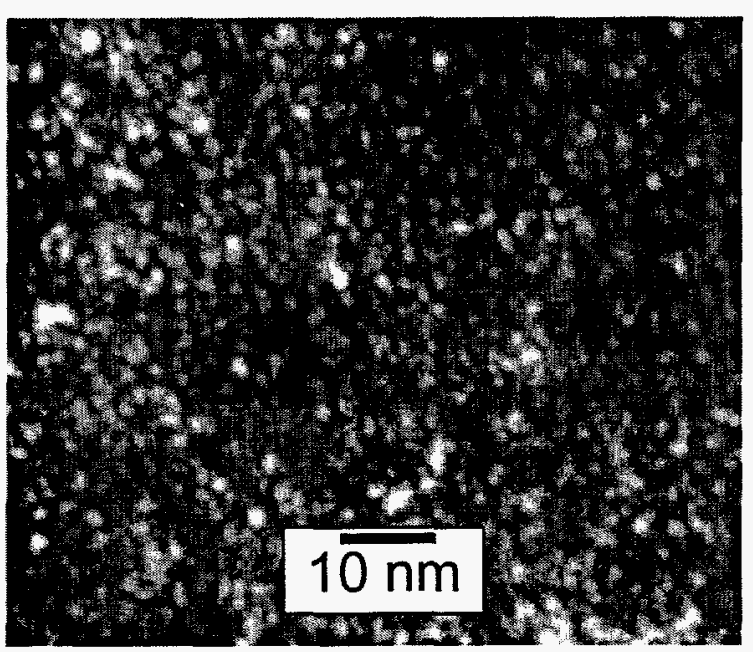

Figure 4 


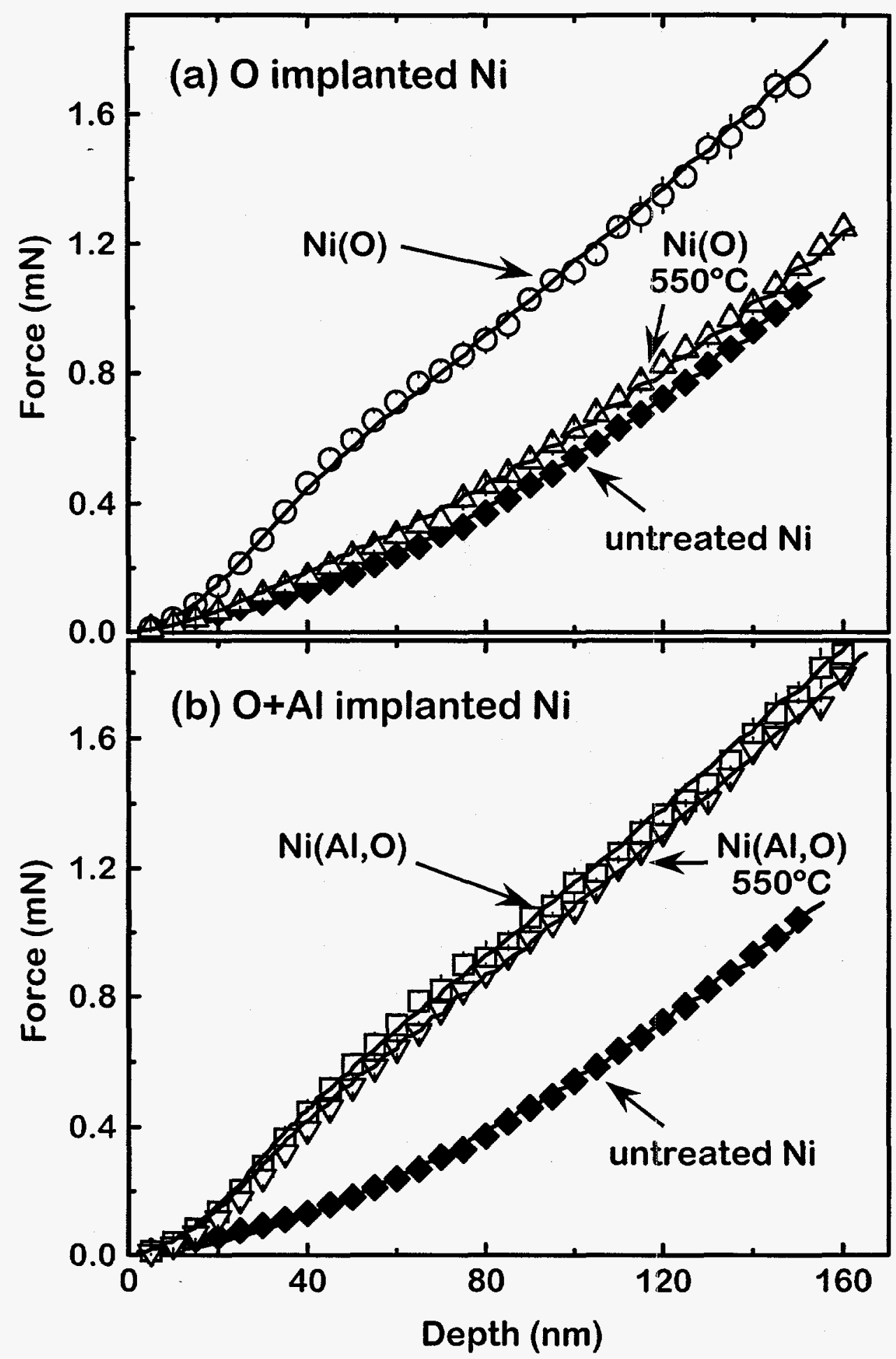

Figure 5 


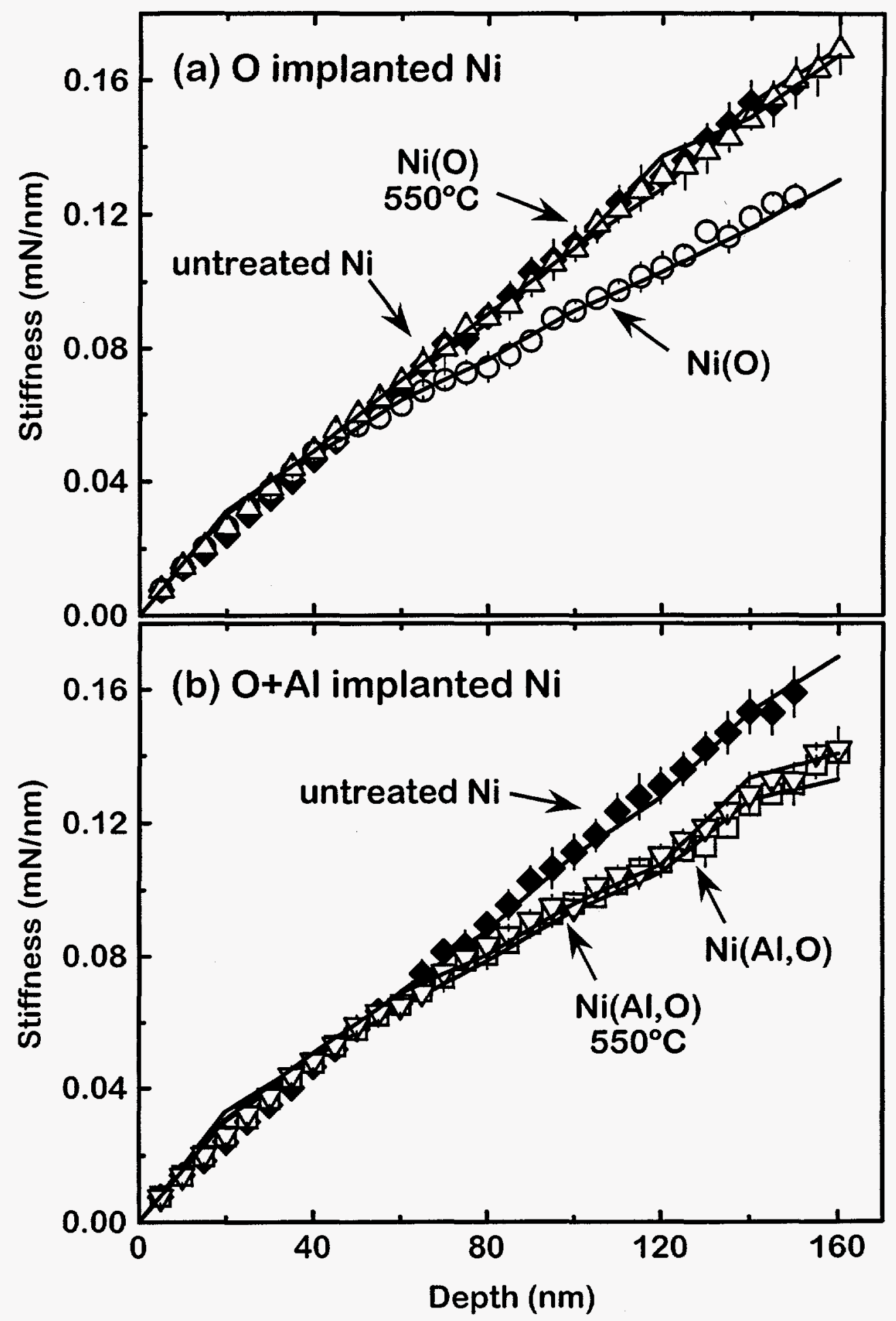

Figure 6 


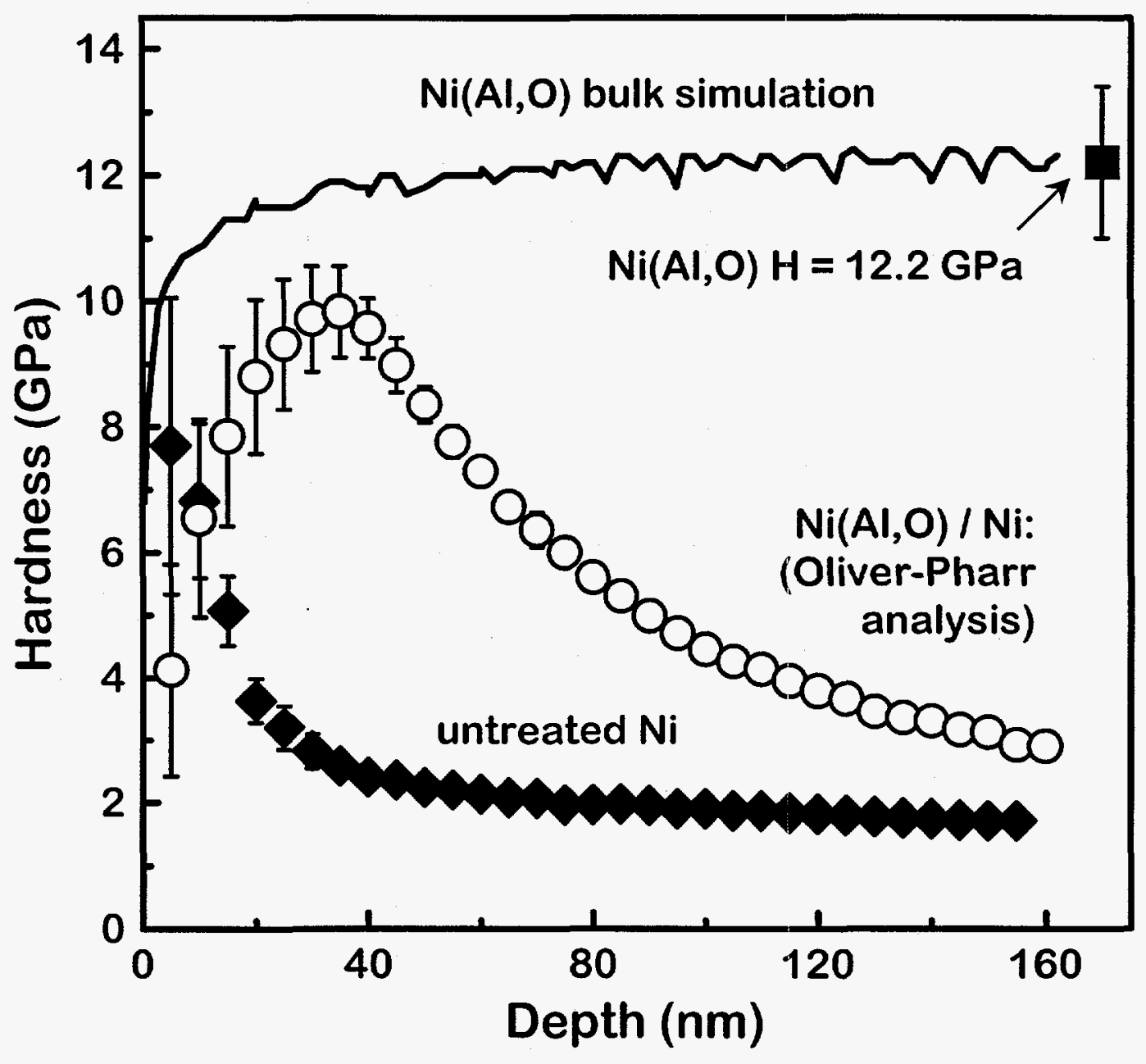

Figure 7 


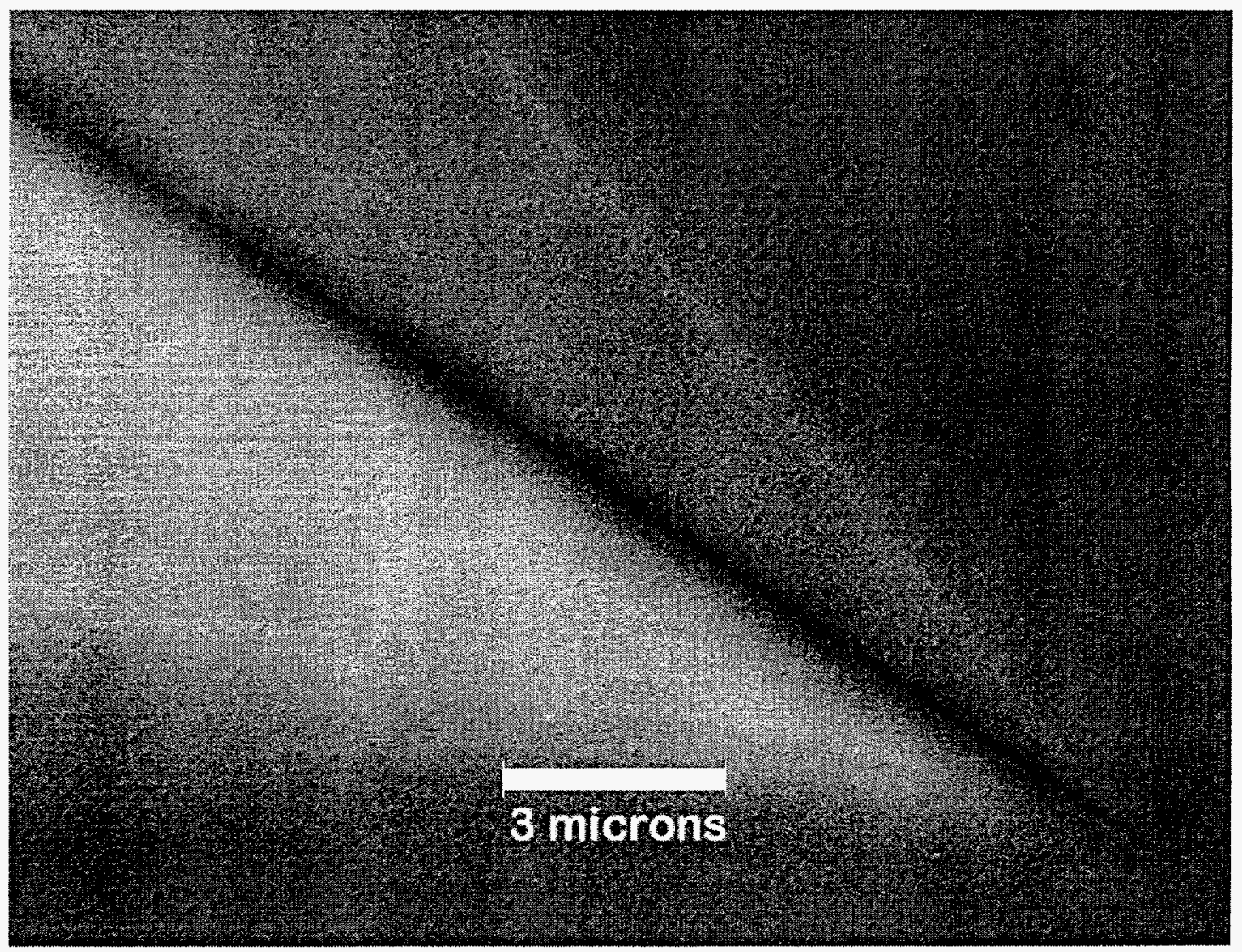

Figure 8 


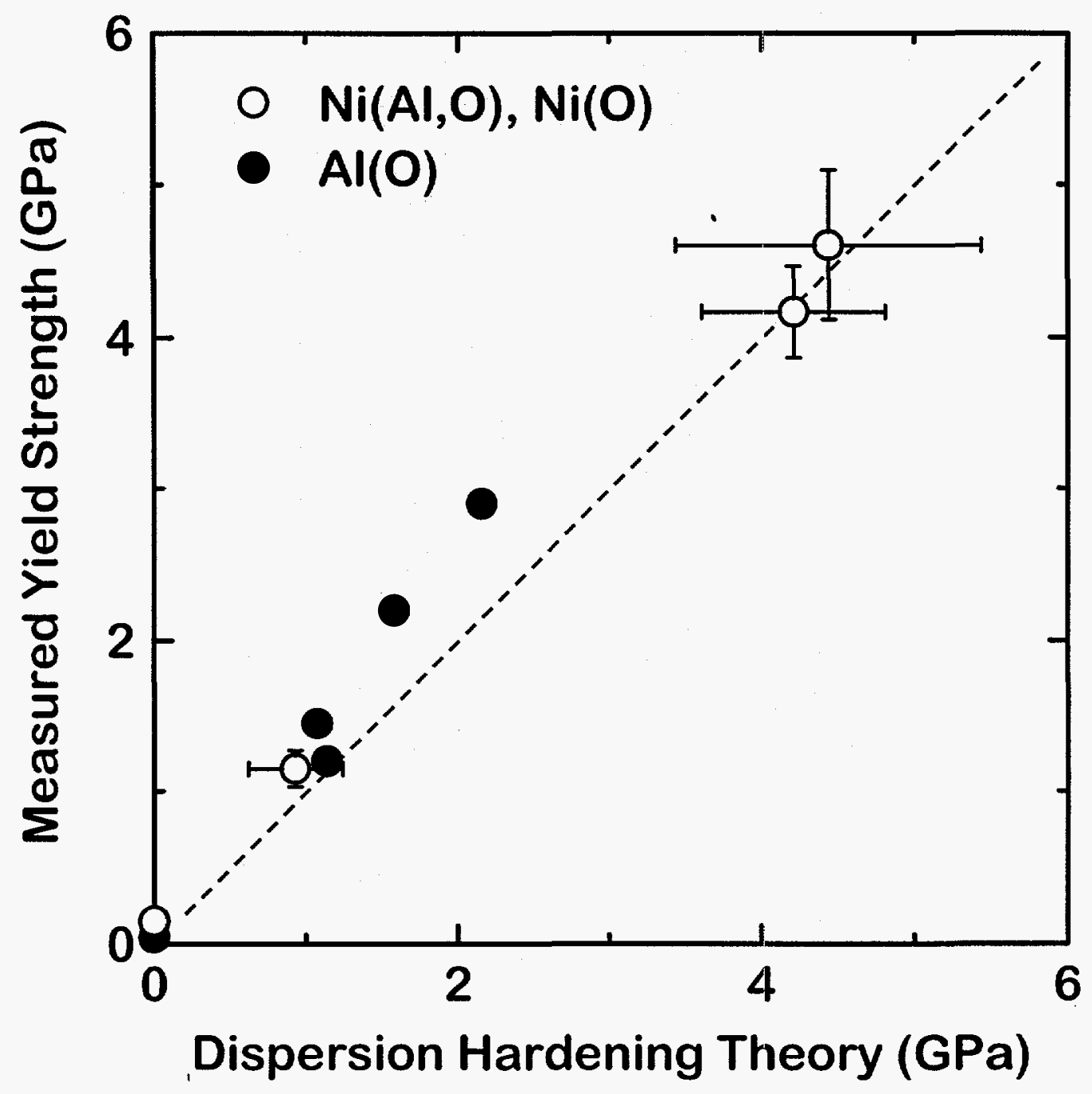

Figure 9 